\title{
PSYCHOLOGY IN CEYLON
}

\author{
J. E. JAYASURIYA \\ University of Ceylon
}

Ceylon has only one University and this too was founded in the year 1942 and is fifteen years old. Naturally therefore both teaching and research in many fields of study are in their early stages of development. In the particular case of psychology, the University of Ceylon does not have a separate department of psychology. It is taught, however, as a subject in three different departments. The Department of Education teaches educational psychology as a subject for the post graduate Diploma in Education, and both educational and social psychology are taught as subjects for the Master's degree in education; the Department of Philosophy teaches psychology to undergraduate students offering philosophy as subject for the Bachelor's degree; and the Department of Sociology teaches psychology to its undergraduate students reading for degrees in sociology. It will be seen that it is in the Department of Education that psychology occupies a prominent place, but the emphasis here is not on pure psychology but on psychology as applied to educational and social problems. As the Department of Education itself is, however, much younger than the rest of the University and is in its ninth year of existence, the output of research is by no means voluminous; nor is it on the other hand negligible, and an attempt will be made to indicate the lines on which research has progressed or is progressing.

Measurement of Intelligence

A group test of intelligence in Sinhalese, the language of the majority of the people of Ceylon, has been fully standardised by the writer for the age range 11 to 15 years and made available to the Government for use in its programme of psychological testing. A non-verbal test has been partially standardised by $\mathrm{C}$. W. Vethanayagam and made available to the Government. Studies have been carried out with various tests published abroad and T. L. Green has reported a study (1) made with the California Test of Mental Maturity. The writer is engaged in studies with Ravan's Progressive Matrices and local norms will be made available shortly. Studies are also in hand with Calvert's Non-Verbal Test, Lule's Multi-Racial Picture Intelligence Test and several other tests. Measurement of Attitudes

Attitude scales based on the Thurstone-Chave technique have been constructed by the writer to measure attitudes towards education and school subjects and several studies using these scales are in progress.

Measurement of Aptitudes and Interests

Studies are being made using McFarlane Smith's test of spatial perception and a modification of the Devon Interest Test devised by Wiseman and Fitz Patrick.

Sociometric Studies

T. L. Green has reported a study (2) using sociometric techniques. A study is being made by the writer of the sociometric status of achievers and non achievers in school.

Psychology of School Subjects

The integration of the school curriculum in mathematics has been discussed by the writer in a paper published in the London Mathematical Gazette (3). The curri- 
culum and methodology of geometry and algebra have also been discussed by the writer in two papers $(4,5)$.

Psychology of Inter-Group Relations

T. L. Green (6) has reported a study using sociometric techniques with a class of school children. The philosophy and psychology of communalism in Ceylon has been discussed by the writer from a theoretical standpoint (7) and from the angle of the contribution schools could make towards eliminating communal tension (8).

Juvenile Delinquency

An analysis of the Case Records of Juvenile Delinquent Probationers has been teported in a joint paper by the writer and Sundari Kariyawasam (9), and the writer has also published a paper on the rehabilitation of the juvenile delinquent (10). Sundari Kariyawasam and the writer are engaged in studies of juvenile delinquency using modifications of certain projective techniques such as the Sentence Completion Test and Rosenzweig's Picture Frustration Test. Shaw's hypothesis of delinquency areas and Cohen's hypothesis of delinquency as the culture of a gang are also being investigated.

Other Studies

A few other studies not belonging to the above categories have been reported and three that are of interest are listed in the references $(11,12,13)$.

There is great scope for psychological study and research in Ceylon and there is no doubt that the coming years will see a great expansion in the volume and quality of psychological research in this country.

\section{REFERENCES}

1. Green, T. L. The effect of the culture pattern on test performance. Teaching, 1953.

2. Green, T. L. Indices of prestige status. Ind. J. Educ. Res., 1953.

3. Jaysuriya, J. E. The integration of the school curriculum in mathematics. Math. Gaz. 1954.

4. Jayasuriya, J. E. The Martians learn geometry. Teaching, 1955.

5. Jayasuriya, J. E. Reflections on the school curriculum in algebra. New Educ., 1957.

6. Green, T. L. Sociometric analysis of sub-cultural cleavages among Ceylonese children. Unir. Ceylon Rev., 1952.

7. Jayasuriya, J. E. Communalism in Ceylon--its philosophy and psychology. Proc. Annual Sessions of the Ceylon Assoc. for the Adrancement of Sci., 1955.

8. Jayasuriya, J. E. What schools could do towards promoting national unity. J. Nat. Educ. Soc. Ceylon, 1955.

9. Jayasuriya, J. E., \& Kariyawasam, S. An analysis of the case records of one hundred juvenile delinquent probationers. Juvenile Probationers in Ceylon, 1956.

10. Jayasuriya, J. E. The rehabilitation of the deliquent. J. Probation, 1956.

11. Pieris, R. Character formation in the evolution of the acquisitive society. Psychiatry, 1952.

12. Jayasuriya, D. L. Dynamics of goal setting behaviour: Task variability and the social determinants of level of aspiration. Univ. of Ceylon Rev. 1957.

13. Jayasuriya, J. E. Some psychological aspects of culture revival. In R. Pieris (Ed.), Traditional Sinhalese culture.

Ms. received IX 26, 57.

Writer : Jayasuriya, J. E. (1918- ) Master of Arts (Lond.), Professor of Education, University of Ceylon. Author of Statistical Calculations for Teachers, A Situational Approach to the English Speech Lesson, etc. Associate of the British Psychological Society. 